Monteiro, F., Canavarro, M. C., \& Pereira, M. (2017). Prevalence and correlates of psychological distress among middle-aged and older women living with HIV. Psychology, Health \& Medicine, 22(9), 1105-1117. doi:10.1080/13548506.2017.1281972

\title{
Prevalence and correlates of psychological distress of middle-aged and older women living with HIV
}

\begin{abstract}
The aims of this study were to examine the prevalence and correlates of psychological distress among older women living with HIV in comparison to their male counterparts and younger women and to identify the sociodemographic and disease-related factors associated with psychological distress. The sample consisted of 508 HIV-infected patients ( 65 older women, 323 women aged below 50 years, and 120 older men) recruited from 10 Portuguese hospitals. Data regarding psychological distress were collected using the Brief Symptom Inventory (BSI). Seven older women (10.8\%), eight older men (6.7\%), and 61 younger women (18.9\%) reported a T-score $\geq 63$ for global severity index (GSI), indicative of a need for further psychological evaluation. Overall, younger women reported significantly higher psychological distress than older men. The odds of having clinically significant psychological distress score were significantly lower for older women reporting sexual transmission, while for younger women, having other co-infections was a significant correlate of higher psychological distress. Younger women were 2.67 (95\% CI: 1.22-5.84) times more likely to report psychological distress than were older men. The odds were not significantly different from older women. This study shows that older women do not differ substantially from younger women and older men in terms of psychological distress. The results reinforce, however, that mental health interventions should be tailored to reflect individuals' circumstances as well as developmental contexts. Moreover, they draw attention to the importance of examining resilience characteristics in older adults to understand the mechanisms behind "successful ageing" while living with HIV.
\end{abstract}

Keywords: Psychological distress; HIV/AIDS; Middle-aged and older adults; Women. 


\section{Introduction}

HIV infection is increasingly affecting adults over the age of 50 years worldwide. Although the HIV epidemic affects all people, its impact on women, and particularly on middle-aged and older (hereafter older for short) women, is often overlooked. A deeper understanding of this group is extremely important, as older women may experience numerous psychosocial and psychological burdens, such as caregiving issues and household responsibilities that may inhibit self-care, financial burdens and employment-related stress, loneliness and lack of social support (for a review, see Durvasula, 2014), which may increase their vulnerability and accordingly contribute to further impairments in their well-being and mental health.

The interest on mental health of people living with HIV/AIDS (PLWHA) has been evidenced in the literature since the beginning of the AIDS epidemic (Chuang, Jason, Pajurkova, \& Gill, 1992; Collins, Holman, Freeman, \& Patel, 2006). However, most mental health research in HIV has relied largely on samples of younger individuals, with an overrepresentation of men. Consequently, little is known about the mental health needs and the psychological distress of older PLWHA, particularly of older women. Older women with HIV are often stigmatized because of myths about ageing or sexuality (Vanable, Carey, Blair, \& Littlewood, 2006) and have the added burden of being a caregiver while living with a chronic medical condition (Hackl, Somlai, Kelly, \& Kalichman, 1997). These aspects may compound the risk for mental health problems (Major \& O'Brien, 2005), as these experiences may serve as additional stressors and contribute to increased difficulties in psychological adjustment (Heckman et al., 2004).

In the general older population, female gender is often portrayed a risk factor for the development of symptoms of psychological distress, particularly depressive and anxiety symptoms (Vink, Aartsen \& Schoevers, 2008). Research has also indicated that psychological distress is more prevalent among HIV-infected women, when compared to men (Gordillo et al., 2009; Robertson et al., 2014) or to uninfected women (Morrison et al., 2002). Regarding age differences, past research has shown evidence of decreased mental health among older HIV patients (Grov, Golub, Parsons, Brennan, \& Karpiak, 2010; Heckman et al., 2002). Despite these findings, a recent literature review suggested that mental health outcomes are less age-dependent (Degroote, Vogelaers, \& Vandijck, 
2014). Among older women with HIV, to our knowledge, there has been limited research specifically addressing the prevalence of psychological distress. Given this dearth of research, further studies are noticeably needed.

Besides the importance of assessing the prevalence of psychological distress among older adults, identifying its sociodemographic and disease-related correlates is also critical to improving their psychological well-being. In this context, existing studies have reported mixed findings. However, there has been some consistency showing an association between better mental health and having a stable partner (Protopopescu et al., 2007), having higher education (Benoit et al., 2014; Murri et al., 2003) and having employment (Blalock, McDaniel, \& Farber, 2002; Rueda et al., 2011). Regarding HIV-related variables, lower CD4+ T-cell counts were associated with decreased mental health (Armon \& Lichtenstein, 2012; Protopopescu et al., 2007), a longer time since HIV diagnosis was associated with both poorer (Zinkernagel et al., 2001) and better mental health (Rueda et al., 2011), and disruption of anti-retroviral therapy was associated with poorer mental health outcomes (Liu et al., 2006). These findings have been reported across multiple samples, most notably among younger PLWHA. Therefore, it is possible that these variables may contribute differently to the psychological distress of older women, a focus that, to our knowledge, has not been the subject of any research.

In this study, the objective was to examine the prevalence and correlates of psychological distress among older women with HIV, compared to their male counterparts and to women less than 50 years. Although the age of 50 is not generally used to identify "elderly" patients, this cut-off is often used in the context of HIV by the Centers for Disease Control and Prevention (CDC) and is recommended to define advanced age in HIV infection (Blanco et al., 2012). A secondary objective was to identify the sociodemographic and disease-related factors associated with psychological distress within these groups.

\section{Methods}

\section{Participants and procedure}

Participants of this study were invited to participate while attending a consultation with their infectious disease specialist. The recruitment procedures have been described with more detail 
elsewhere (Pereira \& Canavarro, 2011). A total of 1,251 patients attending the main departments of infectious diseases of 10 Portuguese hospitals were consecutively recruited by convenience.

Participants who did not complete the set of questionnaires $(n=54)$ or did not report their age $(n=2)$ were excluded. One participant was excluded because (s)he self-identified as transgender. Given the aim of this study, 686 participants (men $<50$ years) were also excluded. The final sample comprised 508 HIV-infected patients: 65 older women (12.8\%), 323 women aged below 50 years $(63.6 \%)$ and 120 older men $(23.6 \%)$.

After a detailed explanation of the study objectives, written informed consent was obtained from all participants. Ethical approval was obtained from the Ethics Committee of all the institutions involved. Participants received no compensation for their participation.

\section{Measures}

Sociodemographic (e.g., age, education, ethnicity) and HIV-related (e.g., HIV stage, CD4+ Tcell count, year of HIV diagnosis) data were collected by self-report and confirmed from the participants' medical records.

Psychological distress was assessed with the 53-item Brief Symptom Inventory (BSI; Derogatis, 1993). Respondents were asked to rate each symptom on a 5-point scale, ranging from 0 (Never) to 4 (Very often). The BSI assesses nine symptom dimensions and three global indices. In this study, being a summary index of psychological distress, the Global Severity Index (GSI) was used. Raw scores were converted to T-scores with a mean value of 50 and a standard deviation $(S D)$ of 10 . According to Derogatis, participants with subscale (dimensions) or GSI T-scores $\geq 63$ were defined as having clinically significant psychological distress. A dummy variable was created to categorize individuals into one group if they had a T-score $<63$ and into a second group if they had a T-score $\geq$ 63 ("caseness" - an indicator of the need for further psychological evaluation). The Cronbach's alphas in this study were all above .72 , with the exception of paranoid ideation ( $\alpha=.67$ for older women).

\section{Data analysis}

Data were analysed using the Statistical Package for Social Sciences (IBM SPSS 22.0). Chisquare analyses were used to assess whether the study groups had different proportions of people above the threshold of the BSI (T-score $\geq 63$ ) for being considered "caseness". Univariate 
(ANCOVA) and multivariate analysis of covariance (MANCOVA) were used to test for group differences in the GSI and symptoms of psychological distress, respectively. Bonferroni adjustments were applied to correct for multiple comparisons $(p<.01)$. Multiple logistic regression analyses were used to identify factors associated with psychological distress.

\section{Results}

\section{Participant characteristics}

The sociodemographic and HIV-related characteristics are displayed in Table 1. Overall, older women had less years of education, were more likely to be widowed and to be diagnosed with HIV for a shorter time. Additionally, they were less likely to be single and to report HIV transmission through intravenous drug use (IDU). No significant differences were found regarding employment status, ethnicity, HIV stage, CD4+ T-cell count, combination anti-retroviral therapy (cART) or the presence of other co-infections.

[Table_1_about_here]

\section{Psychological distress}

Results of the MANCOVA comparing the study groups on the nine psychological symptoms indicated a significant multivariate effect (Wilks' $\lambda=.93, F(18,952)=1.83, p=.018, \eta_{\mathrm{p}}^{2}=.03$ ). Follow-up tests (after Bonferroni correction) indicated differences in three dimensions, with younger women reporting significantly higher scores than older men in interpersonal sensitivity, hostility and paranoid ideation. No significant differences were found between younger and older women or between older women and men (Table 2).

[Table_2_about_here]

\section{Cases and non-cases prevalence}

There were significant differences in the proportion of individuals that scored above the criteria for caseness (Table 3). Compared to older men, a greater proportion of younger women met caseness for interpersonal sensitivity, hostility and paranoid ideation. No significant differences were found between older women and the comparison groups.

[Table_3_about_here]

\section{Correlates of psychological distress}


In the univariate model (Table 4), for older women, the odds of having a clinically significant GSI score were significantly lower for older women reporting sexual transmission (Odds ratio [OR] = $0.15,95 \%$ Confidence Interval [CI]: 0.03-0.86). Among younger women, the only significant correlate of increased psychological distress was having other co-infections. Regarding older men, none of the variables were significantly associated with increased likelihood of psychological distress. [Table_4_about_here]

For older women, the multivariate logistic regression showed that none of the variables were associated with a GSI T-score $\geq 63$. Among younger women, the only factor independently associated with a higher likelihood of psychological distress was the presence of other co-infections. Because in the male group only one variable was associated with a GSI T-score $\geq 63$ for $p<.20$, the multivariate model was not computed.

These analyses were also conducted in the total sample, adding the study groups as an independent variable. The univariate model (Table 5) indicated that compared to older men, younger women were 3.26 times more likely to report psychological distress (95\% CI: 1.51-7.04). In the multivariate model, only the age-group was an independent correlate of psychological distress. Reinforcing the univariate results, younger women were almost 3 times more likely to report with a GSI T-score $\geq 63$, compared to older men.

[Table_5_about_here]

\section{Discussion}

This study examined the prevalence and correlates of psychological distress among older women with HIV, compared to their male counterparts and to women less than 50 years old. The results indicated greater psychological distress among younger women when compared to older men (the odds of being assessed with clinically psychological distress was 1.22 to 5.84 times higher among younger women). A possible explanation may be the myriad of psychosocial stressors observed in HIV-infected women, such as financial and housing problems, caregiving tasks, relationship problems or even abandonment (Durvasula, 2014; Gurung, Kemeny, \& Myers, 2004), which may not affect so prominently their male counterparts. An alternate explanation may be the unique biological aspects that HIV-infected women face, such as health changes due to menopause or early transition to 
menopause (Andany, Kennedy, Aden, \& Loutfy, 2016; Tariq, Delpech, \& Anderson, 2016), which have been associated with a significant prevalence of psychological symptoms (Ferreira et al., 2007; Maki et al., 2012). All these factors may serve as additional stressors, and coping with these cumulative effects may be psychologically demanding for most women living with HIV.

These findings may also reflect a possible "successful ageing", which has been recently highlighted in several studies (Emlet, Tozay, \& Raveis, 2011; Fang et al., 2015; Moore et al., 2013). Despite HIV and age-related consequences, there is evidence showing that older adults seem to demonstrate strengths and even decreased symptoms of depression and anxiety when compared to younger adults (McGowan et al., 2016). In our study, gender seems to play a more salient role in the prevalence of psychological distress. Besides the differences that were found between younger women and older men, there was also a trend indicating that older women reported higher scores than older men in all psychological symptoms, although the results did not achieve statistical significance. Hence, there is no doubt that mental health issues are an essential topic, as this segment of the population is likely to be most prevalent in the years to come. Accordingly, because women, compared to their male counterparts, face many unique challenges that greatly influences well-being, developing mental health interventions appropriate for age and also reflecting women's and men's distinctive vulnerabilities are of major relevance.

Fifteen percent of the sample reported psychological distress beyond the threshold considered clinically significant for the BSI. This value is similar to those reported by other studies in which the same measure has been used (Basta, Shacham, \& Reece, 2009; Shacham, Basta, \& Reece, 2008). These results are lower than those reported by Benoit et al. (2014), although the fact that a different measure was used (Kessler Psychological Distress Scale) may account for this difference. These results are consistent with prior studies indicating that psychological distress was more prevalent among HIV-infected women when compared to men (Gordillo et al., 2009; Robertson et al., 2014). In part, our findings also support those found in the general population, indicating that young people experience a higher prevalence of psychological distress, compared to older groups, regardless of the presence of chronic medical conditions, sociodemographic, and other health-related variables (Chittleborough, Winefield, Gill, Koster, \& Taylor, 2011). 
Regarding the psychological symptoms, younger women reported significantly higher scores on interpersonal sensitivity, hostility and paranoid ideation than older men. These results suggest that younger women seem to be harbouring more anger/hostility behaviours towards others, either because of lack of interpersonal skills, as a protective measure to buffer the psychological impact of HIVrelated stigma and discrimination or as an expression of the mode of transmission. In this sample, a further analysis suggested a trend for younger women reporting IDU having higher scores on hostility than older men (Mean: 54.22 vs. 45.77 ) as well as men and women reporting other modes of transmission. This result is in line with prior evidence suggesting that substance abusers experience more anger than nonusers (DeMoja \& Spielberger, 1997). Cumulatively, these behaviours can therefore induce an environment where important sources of support may not be received. Though anger/hostility has been recently associated with younger age in HIV-infected patients (McIntosh et al., 2015), the synergistic role of age, gender and mode of HIV transmission warrants further exploration. Nevertheless, because such psychological dimensions may have detrimental effects on individuals' interpersonal functioning, interventions that taught interpersonal skills, such as assertiveness training and anger management (Antoni, 2003), may be of value for younger women.

The mode of transmission was a significant correlate of psychological distress among older women, with those reporting transmission through IDU being more likely to report clinically significant psychological distress. Recently, among HIV-infected women of all ages, Benoit et al. (2014) found that not reporting IDU in the last six months was associated with decreased psychological distress, which is partially consistent with our results. A possible explanation may be the previous history of drug and substance, which has been associated with poorer mental health in HIV-infected patients (Degroote et al., 2013; Korthuis et al., 2008), including in all-female samples (te Vaarwerk \& Gaal, 2001). Because we do not have data regarding current drug use, future studies are warranted to better understand this association.

Among younger women, the presence of other co-infections (in this study, 44 out of 60 women with co-infections had hepatitis $\mathrm{C}$ virus $[\mathrm{HCV}]$ ) was associated with higher odds of psychological distress. This is noteworthy as there has been evidence of a positive association between psychological distress and the presence of HIV in combination with other infections, and 
particularly hepatitis C (Pereira, Fialho, \& Canavarro, 2014). However, because research in the area of co-infections has focused on mixed (predominantly male) or exclusively male samples, additional studies specifically focusing on women are needed. This is particularly relevant for younger women, as most are of reproductive age (in this study, $73.3 \%$ were below 40 years) and, for example, it has been shown that HIV/HCV co-infected mothers have significantly increased likelihood of vertical HCV transmission than do women with HCV alone (Polis, Shah, Johnson, \& Gupta, 2007).

This study is not without limitations. The cross-sectional design, which precludes any causal associations, and the convenience sample require caution in interpreting and generalizing these findings. Psychological distress was assessed with the BSI, a self-reported screening tool that has been frequently used in HIV research (Basta et al., 2009; Brown et al., 2015). Although the BSI is a well-known and reliable index of psychological distress and assesses a wide range of psychological symptoms, the validity of its factorial structure has been questioned (Loutsiou-Ladd, Panayiotou, \& Kokkinos, 2008). Thus, a cautious approach in interpreting the subscale profile scores is important. Other variables that were not collected, such as financial burden, close relationships and social support, resilience characteristics, coping skills and stigma (related to both HIV and age) could add significant inputs for our findings. The assessment of these variables may be pertinent to clarify the factors and/or mechanisms underlying the concept of "successful ageing". In this context, studies comparing older PLWHA and older individuals without HIV would also be valuable. Because menopause is also an important part of ageing and that women with HIV are at higher risk of developing early and premature menopause (Andany et al., 2016), in future studies it would be also relevant the comparison of mental health outcomes considering the age of menopause onset. Although the overall sample was of a reasonable size, there is considerable heterogeneity in sample size across the three groups, and the number of women aged 50 years and older was much smaller than the group of younger women. Finally, the sample comprised a relevant proportion of middle-aged patients rather than the elderly (adults aged 65 years and older, as conventionally defined by the World Health Organization - in this study, only $15.1 \%$ of patients were above 65 years). Therefore, these results must be viewed as preliminary and in need of replication and extension. 
Despite these limitations, this study has important strengths. This study shows that psychological distress in PLWHA includes not only depression and anxiety but also a wide range of psychopathological symptoms that should be contemplated when considering mental health in HIV. Most importantly, these findings contribute to the scarce literature on the mental health of middleaged and older women with HIV, being, to our knowledge, the first study examining the prevalence and correlates of psychological distress in this group of the HIV population.

In conclusion, as the prevalence of older PLWHA is expected to increase, addressing their mental health needs and recognizing the diversity of individual circumstances and developmental contexts are increasingly needed. In this regard, the training of age-specialized mental health providers is of major relevance, and new treatment paradigms (encompassing a comprehensive and integrated care) are needed to cope with this emergent population (Justice, 2010). Finally, as psychological distress was not highest among the older age-groups, our findings also draw attention to the importance of examining resilience characteristics of older adults to understand the mechanisms behind successful ageing while living with HIV. Importantly, a greater attention to younger women is also needed to prevent further impairments in physical and mental health.

\section{Disclosure Statement}

The authors declare that they have no conflict of interest.

\section{Acknowledgements}

This study was supported by Coordenação Nacional para a Infecção VIH/sida (Grant: Ref. 51.8.4/2007) and it was developed within the research group "Relationships, Development \& Health", of the R\&D Unit CINEICC Cognitive and Behavioural Centre for Research and Intervention, University of Coimbra. Marco Pereira is FCT Researcher (IF/00402/2014) and was supported by a Post-doctoral Scholarship from the Portuguese Foundation for Science and Technology (SFRH/BPD/44435/2008). 


\section{References}

Andany, N., Kennedy, V. L., Aden, M., \& Loutfy, M. (2016). Perspectives on menopause and women with HIV. International Journal of Women's Health, 8, 1-22. doi:10.2147/IJWH.S62615

Antoni, M. H. (2003). Stress management effects on psychological, endocrinological, and immune functioning in men with HIV infection: Empirical support for a psychoneuroimmunological model. Stress, 6, 173-188. doi:10.1080/1025389031000156727

Armon, C., \& Lichtenstein, K. (2012). The associations among coping, nadir CD4+ T-cell count, and non-HIV-related variables with health-related quality of life among an ambulatory HIVpositive patient population. Quality of Life Research, 21, 993-1003. doi:10.1007/s11136-011$0017-2$

Basta, T., Shacham, E., \& Reece, M. (2009). Symptoms of psychological distress: A comparison of rural and urban individuals in HIV-related mental health care. AIDS Patient Care and STDs, 23, 1053-1057. doi:10.1089/apc.2009.0193

Benoit, A. C., Light, L., Burchell, A. N., Gardner, S., Rourke, S. B.,Wobeser, W., \& Loutfy, M. R. (2014). Demographic and clinical factors correlating with high levels of psychological distress in HIV-positive women living in Ontario, Canada, AIDS Care, 26, 694-701. doi:10.1080/09540121.2013.855301

Blalock, A. C., McDaniel, J. S., \& Farber, E. W. (2002). Effect of employment on quality of life and psychological functioning in patients with HIV/AIDS. Psychosomatics, 43, 400-404. doi:10.1176/appi.psy.43.5.400

Blanco, J. R., Jarrín, I., Vallejo, M., Berenguer, J., Solera, C., Rubio, R., ... CoRIS, S. (2012). Definition of advanced age in HIV infection: Looking for an age cut-off. AIDS Research and Human Retroviruses, 28, 1000-1006. doi:10.1089/aid.2011.0377

Brown, L. K., Whiteley, L., Harper, G. W., Nichols, S., Nieves, A. \& The ATN 086 Protocol Team for The Adolescent Medicine Trials Network for HIV/AIDS Interventions (2015). Psychological symptoms among 2032 youth living with HIV: A multisite study. AIDS Patient Care and STDs, 29, 212-219. doi:10.1089/apc.2014.0113 
Centers for Disease Control and Prevention [CDC] (1992). 1993 revised classification system for HIV infection and expanded surveillance case definition for AIDS among adolescents and adults. MMWR Recommendations and Reports, 41(RR-17), 1-19. Retrieved from www.cdc.gov/mmwr/preview/mmwrhtml/00018871.htm

Chittleborough, C. R., Winefield, H., Gill, T. K., Koster, C., \& Taylor, A. W. (2011). Age differences in associations between psychological distress and chronic conditions. International Journal of Public Health, 6, 71-80. doi:10.1007/s00038-010-0197-5

Chuang, H. T., Jason, G. W., Pajurkva, E. M., \& Gill, M. J. (1992). Psychiatric morbidity in patients with HIV infection. Canadian Journal of Psychiatry, 37, 109-115.

Collins, P. Y., Holman, A. R., Freeman, M. C., \& Patel, V. (2006). What is the relevance of mental health to HIV/AIDS care and treatment programs in developing countries? A systematic review. AIDS, 20, 1571-1582. doi:10.1097/01.aids.0000238402.70379.d4

De Mojá, C. A., \& Spielberger, C. D. (1997). Anger and drug addiction. Psychological Reports, 81, 152-154. doi:10.2466/pr0.1997.81.1.152

Degroote, S., Vogelaers, D., \& Vandijck, D. M. (2014). What determines health-related quality of life among people living with HIV: An updated review of the literature. Archives of Public Health, 72(1), 40. doi:10.1186/2049-3258-72-40

Degroote, S., Vogelaers, D. P., Vermeir, P., Mariman, A., De Rick, A., Van Der Gucht, B., ... Vandijck D. M. (2013). Socio-economic, behavioural, (neuro)psychological and clinical determinants of HRQoL in people living with HIV in Belgium: A pilot study. Journal of the International AIDS Society, 16, 18643. doi:10.7448/IAS.16.1.18643

Derogatis, L.R. (1993). BSI: Brief Symptom Inventory: administration, scoring and procedures manual. Minneapolis: Natural Computers System.

Durvasula, R. (2014). HIV/AIDS in older women: Unique challenges, unmet needs. Behavioral Medicine, 40, 85-98. doi:10.1080/08964289.2014.893983.

Emlet, C. A,. Tozay, S., \& Raveis, V. (2011).“I'm not going to die from the AIDS”: Resilience in aging with HIV disease. Gerontologist, 51, 101-111. doi:10.1093/geront/gnq060 
Fang, X., Vincent, W., Calabrese, S. K., Heckman, T. G., Sikkema, K. J., Humphries, D. L., \& Hansen, N. B. (2015). Resilience, stress, and life quality in older adults living with HIV/AIDS. Aging \& Mental Health. doi:10.1080/13607863.2014.1003287

Ferreira, C. E., Pinto-Neto, A. M., Conde, D. M., Costa-Paiva, L., Morais, S. S., \& Magalhães, J. (2007). Menopause symptoms in women infected with HIV: Prevalence and associated factors. Gynecological Endocrinology, 23, 198-205. doi:10.1080/09513590701253743

Gordillo, V., Fekete, E. M., Platteau, T., Antoni, M. H., Schneiderman, N., \& Nöstlinger, C. (2009). Emotional support and gender in people living with HIV: Effects on psychological wellbeing. Journal of Behavioral Medicine, 32, 523-531. doi:10.1007/s10865-009-9222-7

Grov, C., Golubb, S. A., Parsons, J. T., Brennane, M., \& Karpiak, S. E. (2010). Loneliness and HIVrelated stigma explain depression among older HIV-positive adults. AIDS Care, 22, 630-639. doi:10.1080/09540120903280901

Gurung, R. A. R., Kenemy, M. E., \& Myers, H. (2004). HIV is not my biggest problem?: The impact of HIV and chronic burden on depression in women at risk for Aids. Journal of Social and Clinical Psychology, 23, 490-511. doi:10.1521/jscp.23.4.490.40305

Hackl, K. L., Somlai, A. M., Kelly, J. A., \& Kalichman, S. C. (1997). Women living with HIV/AIDS: The dual challenge of being a patient and caregiver. Health and Social Work, 22, 53-62. doi:10.1093/hsw/22.1.53

Heckman, T. G., Anderson, E. S., Sikkema, K. J., Kochman, A., Kalichman, S. C., \& Anderson, T. (2004). Emotional distress in nonmetropolitan persons living with HIV disease enrolled in a telephone-delivered, coping improvement group intervention. Health Psychology, 23, 94-100. doi:10.1037/0278-6133.23.1.94

Heckman, T. G., Heckman, B. D., Kochman, A., Sikkema, K. J., Suhr, J., \& Goodkin, K. (2002). Psychological symptoms among persons 50 years of age and older living with HIV disease. Aging \& Mental Health, 6, 121-128. doi:10.1080/13607860220126709a

Justice, A. C. (2010). HIV and aging: Time for a new paradigm. Current HIV/AIDS Reports, 7, 69-76. doi:10.1007/s11904-010-0041-9 
Korthuis, P. T., Zephyrin, L. C., Fleishman, J. A., Saha, S., Josephs, J. S., McGrath, M. M., ... Gebo, K. A. (2008). Health-related quality of life in HIV-infected patients: The role of substance use. AIDS Patient Care STDS, 22, 859-867. doi:10.1089/apc.2008.0005

Liu, C., Johnson, L., Ostrow, D., Silvestre, A., Visscher, B., \& Jacobson, L. P. (2006). Predictors for lower quality of life in the HAART era among HIV-infected men. Journal of Acquired Immune Deficiency Syndromes, 42, 470-477. doi:10.1097/01.qai.0000225730.79610.61

Loutsiou-Ladd, A., Panayiotou, G., \& Kokkinos, C. M. (2008). A review of the factorial structure of the Brief Symptom Inventory (BSI): Greek evidence. International Journal of Testing, 8, 90110. doi:10.1080/15305050701808680

Major, B., \& O’Brien, L. T. (2005). The social psychology of stigma. Annual Review of Psychology, 56, 393-421. doi:10.1146/annurev.psych.56.091103.070137

Maki, P. M., Rubin, L. H., Cohen, M., Golub, E. T., Greenblatt, R. M., Young, M., ... Cook, J. A. (2012). Depressive symptoms are increased in the early perimenopausal stage in ethnically diverse HIV+ and HIV- women. Menopause, 19, 1215-1223. doi:10.1097/gme.0b013e318255434d

McGowan, J., Sherr, L., Rodger, A., Fisher, M., Miners, A., Anderson, J., ... the Antiretrovirals, Sexual Transmission Risk and Attitudes (ASTRA) Study Group (2016). Age, time living with diagnosed HIV infection, and self-rated health. HIV Medicine. Advance online publication. doi:10.1111/hiv.12398

McIntosh, R. C., Hurwitz, B. E., Antoni, M., Gonzalez, A., Seay, J., \& Schneiderman, N. (2015). The $\mathrm{ABCs}$ of trait anger, psychological distress, and disease severity in HIV. Annals of Behavioral Medicine, 49, 420-433. doi:10.1007/s12160-014-9667-y

Moore, R. C., Moore, D. J., Thompson, W., Vahia, I. V., Grant, I., \& Jeste, D. V. (2013). A casecontrolled study of successful aging in older adults with HIV. Journal of Clinical Psychiatry. 74, 417-423. doi:10.4088/JCP.12m08100

Morrison, M. F., Petitto, J. M., Ten Have, T., Gettes, D. R., Chiappini, M. S., Weber, A. L., ... Evans, D. L. (2002). Depressive and anxiety disorders in women with HIV infection. American Journal of Psychiatry, 159, 789-796. doi:10.1176/appi.ajp.159.5.789 
Murri, R., Fantoni, M., Del Borgo, C., Visona, R., Barracco, A., Zambelli, A., ... Wu, A. W. (2003). Determinants of health-related quality of life in HIV-infected patients. AIDS Care, 15, 581-590. doi:10.1080/0954012031000134818

Pereira, M., \& Canavarro, M. C. (2011). Gender and age differences in quality of life and the impact of psychopathological symptoms among HIV-infected patients. AIDS and Behavior, 15, 18571869. doi:10.1007/s10461-011-9928-8

Pereira, M., Fialho, R., \& Canavarro, M. C. (2014). Prevalence and correlates of emotional distress in HIV/HCV co-infection. AIDS Care, 26(Suppl.1), S56-S64. doi:10.1080/09540121.2014.906549

Polis, C. B., Shah, S. N., Johnson, K. E., \& Gupta, A. (2007). Impact of maternal HIV coinfection on the vertical transmission of hepatitis C virus: A meta-analysis. Clinical Infectious Diseases, 44 , 1123-1131. doi:10.1086/512815

Protopopescu, C., Marcellin, F., Spire, B., Preau, M., Verdon, R., Peyramond. D., ... Carrieri, M. P. (2007). Health-related quality of life in HIV-1-infected patients on HAART: A five-years longitudinal analysis accounting for dropout in the APROCO-COPILOTE cohort (ANRS CO8). Quality of Life Research, 16, 577-591. doi:10.1007/s11136-006-9151-7

Robertson, K., Bayon, C., Molina, J. M., McNamara, P., Resch, C., Muñoz-Moreno, J. A., ... van Wyk, J. (2014). Screening for neurocognitive impairment, depression, and anxiety in HIVinfected patients in Western Europe and Canada. AIDS Care, 26, 1555-1561. doi:10.1080/09540121.2014.936813

Rueda, S., Raboud, J., Mustard, C., Bayoumi, A., Lavis, J. N., \& Rourke, S. B. (2011). Employment status is associated with both physical and mental health quality of life in people living with HIV. AIDS Care, 23, 435-443. doi:10.1080/09540121.2010.507952

Shacham, E., Basta, T., \& Reece, M. (2008). Symptoms of psychological distress among African Americans seeking HIV-related mental health care. AIDS Patient Care and STDs, 22, 413-421. doi:10.1089/apc.2007.0177

Tariq, S., Delpech, V., \& Anderson, J. (2016). The impact of the menopause transition on the health and wellbeing of women living with HIV: A narrative review. Maturitas, 88, 76-83. doi:10.1016/j.maturitas.2016.03.015 
te Vaarwerk, M. J., \& Gaal, E. A. (2001). Psychological distress and quality of life in drug-using and non-drug-using HIV-infected women. European Journal of Public Health, 11, 109-115. doi:10.1093/eurpub/11.1.109

Vanable, P. A., Carey, M. P., Blair, D. C., \& Littlewood, R. A. (2006). Impact of HIV-related stigma on health behaviors and psychological adjustment among HIV-positive men and women. AIDS and Behavior, 10, 473-482. doi:10.1007/s10461-006-9099-1

Vink, D., Aartsen, M. J., \& Schoevers, R. A. (2008). Risk factors for anxiety and depression in the elderly: A review. Journal of Affective Disorders, 106, 29-44. doi:10.1016/j.jad.2007.06.005

Zinkernagel, C., Taffé, P., Rickenbach, M., Amiet, R., Ledergerber, B., Volkart, A. C., ... Battegay, M. (2001). Swiss HIV Cohort Study: Importance of mental health assessment in HIV-infected outpatients. Journal of Acquired Immune Deficiency Syndromes, 28, 240-249.

doi:10.1097/00042560-200111010-00006 
Table 1

Sociodemographic and HIV-related characteristics of the study groups

\begin{tabular}{|c|c|c|c|c|c|}
\hline & $\begin{array}{c}\text { Women } \geq 50 \\
\text { years } \\
(n=65)\end{array}$ & $\begin{array}{c}\text { Women }<50 \\
\text { years } \\
(n=323)\end{array}$ & $\begin{array}{c}\text { Men } \geq 50 \\
\text { years } \\
(n=120)\end{array}$ & $F / \chi^{2}$ & $\begin{array}{c}\eta_{\mathrm{p}}^{2} / \\
\text { Cramer's } V\end{array}$ \\
\hline Age (years) & $57.58 \pm 6.07$ & $36.56 \pm 6.73$ & $57.98 \pm 7.17$ & & \\
\hline Education (years) & $5.83 \pm 3.56$ & $8.32 \pm 3.99$ & $7.34 \pm 4.98$ & $10.35 * * *$ & .04 \\
\hline Time since HIV diagnosis (years) & $5.52 \pm 4.87$ & $7.85 \pm 5.09$ & $6.79 \pm 5.33$ & $6.29 * *$ & .03 \\
\hline Marital status & & & & $35.26 * * *$ & .19 \\
\hline Single & 4.6 & 33.4 & 20.8 & & \\
\hline Married/co-habiting & 49.2 & 42.2 & 51.7 & & \\
\hline Separated/divorced & 27.7 & 17.8 & 22.5 & & \\
\hline Widowed & 18.5 & 6.6 & 5.0 & & \\
\hline Employment status & & & & 5.95 & .11 \\
\hline Employed & 29.2 & 43.0 & 47.5 & & \\
\hline Not currently working & 70.8 & 57.0 & 52.5 & & \\
\hline Ethnicity & & & & 7.66 & .09 \\
\hline Caucasian & 83.1 & 76.5 & 85.8 & & \\
\hline African & 4.6 & 9.6 & 4.2 & & \\
\hline Other/Unknown & 12.3 & 13.9 & 10.0 & & \\
\hline Mode of transmission & & & & $336.44 * * *$ & .58 \\
\hline Sexual intercourse with man & 86.2 & 71.2 & 11.8 & & \\
\hline Sexual intercourse with woman & 0.0 & 0.3 & 67.2 & & \\
\hline IV Drug use & 3.1 & 22.3 & 10.9 & & \\
\hline Blood products & 7.7 & 2.2 & 6.7 & & \\
\hline Unknown & 3.1 & 4.1 & 3.4 & & \\
\hline HIV stage & & & & 5.48 & .07 \\
\hline Asymptomatic & 60.0 & 64.4 & 67.2 & & \\
\hline Symptomatic & 16.9 & 11.2 & 16.0 & & \\
\hline AIDS & 16.9 & 17.2 & 13.4 & & \\
\hline Unknown & 6.2 & 7.2 & 3.4 & & \\
\hline CD4+ T-cell count ${ }^{\mathrm{a}}$ & & & & 4.19 & .07 \\
\hline$<200$ cells $/ \mathrm{mm}^{3}$ & 23.2 & 18.6 & 19.6 & & \\
\hline 201 e 499 cells $/ \mathrm{mm}^{3}$ & 33.9 & 43.9 & 49.5 & & \\
\hline$>500$ cells $/ \mathrm{mm}^{3}$ & 42.9 & 37.5 & 30.8 & & \\
\hline cART & & & & 3.68 & .09 \\
\hline Yes & 61.4 & 68.3 & 75.5 & & \\
\hline No & 38.6 & 31.7 & 24.5 & & \\
\hline Other co-infections & & & & 3.98 & .09 \\
\hline Yes & 10.8 & 18.6 & 12.5 & & \\
\hline No & 89.2 & 81.4 & 87.5 & & \\
\hline
\end{tabular}

Note: Continuous variables presented as mean \pm standard deviation; categorical variables are presented as percentage (\%); ${ }^{\text {a }} \mathrm{CD} 4 \mathrm{~T}$-cell count was stratified into three groups based on clinically meaningful cut-off points: $<200$ cells $/ \mathrm{mm} 3,201-499$ cells/mm3; and $>500$ cells/mm3 (CDC, 1992).

$* * p<.01 ; * * * p<.001$ 
Table 2

Descriptive statistics (T-scores) of the psychopathological symptoms for the three study groups (adjusted for covariates ${ }^{\mathrm{a}}$ )

\begin{tabular}{|c|c|c|c|c|c|}
\hline & (A) & (B) & (C) & \multirow{3}{*}{$F$} & \multirow{3}{*}{ Post hoc } \\
\hline & $\begin{array}{c}\text { Women } \geq 50 \text { years } \\
(n=65)\end{array}$ & $\begin{array}{c}\text { Women }<50 \text { years } \\
\qquad(n=323)\end{array}$ & $\begin{array}{c}\text { Men } \geq 50 \text { years } \\
(n=120)\end{array}$ & & \\
\hline & $M(S E)$ & $M(S E)$ & $M(S E)$ & & \\
\hline Somatization & $52.29(1.30)$ & $51.28(0.58)$ & $48.93(0.95)$ & 3.00 & \\
\hline Obsessions-Compulsions & $51.12(1.35)$ & $50.93(0.60)$ & $48.35(0.98)$ & 2.74 & \\
\hline Interpersonal sensitivity & $49.51(1.36)$ & $51.49(0.60)$ & $47.93(0.98)$ & $4.88 * *$ & $\mathrm{~B}>\mathrm{C}$ \\
\hline Depression & $51.27(1.35)$ & $50.95(0.60)$ & $48.61(0.98)$ & 2.32 & \\
\hline Anxiety & $51.27(1.31)$ & $51.16(0.58)$ & $46.71(0.95)$ & 3.48 & \\
\hline Hostility & $48.49(1.26)$ & $51.27(0.56)$ & $47.40(0.91)$ & $7.20 * *$ & $\mathrm{~B}>\mathrm{C}$ \\
\hline Phobic anxiety & $50.50(1.36)$ & $51.37(0.60)$ & $48.81(0.99)$ & 2.43 & \\
\hline Paranoid ideation & $48.81(1.26)$ & $50.88(0.56)$ & $47.62(0.92)$ & $4.84 * *$ & $\mathrm{~B}>\mathrm{C}$ \\
\hline Psychoticism & $49.34(1.29)$ & $50.65(0.57)$ & $48.48(0.93)$ & 2.04 & \\
\hline Global Severity Index (GSI) ${ }^{b}$ & $50.56(1.32)$ & $51.25(0.59)$ & $48.02(0.96)$ & 4.12 & \\
\hline
\end{tabular}

${ }^{a}$ Multivariate analysis of variance adjusted for education, marital status, mode of HIV transmission and time since HIV diagnosis.

${ }^{\mathrm{b}}$ Univariate analysis of variance adjusted for education, marital status, mode of HIV transmission and time since HIV diagnosis.

$* * p<.01$ 
Table 3

Proportion of the study groups meeting criteria for caseness (T-score $\geq 63$ )

\begin{tabular}{|c|c|c|c|c|c|}
\hline & $\begin{array}{c}\text { Women } \geq 50 \text { years } \\
\qquad(n=65)\end{array}$ & $\begin{array}{c}\text { Women }<50 \text { years } \\
\qquad(n=323)\end{array}$ & $\begin{array}{c}\text { Men } \geq 50 \text { years } \\
(n=120)\end{array}$ & $\chi^{2}$ & Cramer's $V$ \\
\hline & $n(\%)$ & $n(\%)$ & $n(\%)$ & & \\
\hline Somatization & $13(20.0)$ & $50(15.5)$ & $11(9.2)$ & 4.57 & .10 \\
\hline Obsessions-Compulsions & $9(13.8)$ & $51(15.8)$ & $13(10.8)$ & 1.76 & .06 \\
\hline Interpersonal sensitivity & $7(10.8)$ & $57(17.6)$ & $7(5.8)$ & $10.79 * *$ & .15 \\
\hline Depression & $12(18.5)$ & $52(16.1)$ & $12(10.0)$ & 3.28 & .08 \\
\hline Anxiety & $11(16.9)$ & $53(16.4)$ & $12(10.0)$ & 3.05 & .08 \\
\hline Hostility & $5(7.7)$ & $57(17.6)$ & $9(7.5)$ & $9.94 * *$ & .14 \\
\hline Phobic anxiety & $11(16.9)$ & $54(16.7)$ & $11(9.2)$ & 4.15 & .09 \\
\hline Paranoid ideation & $8(12.3)$ & $54(16.7)$ & $7(5.8)$ & $8.94 *$ & .13 \\
\hline Psychoticism & $10(15.4)$ & $53(16.4)$ & $12(10.0)$ & 2.88 & .08 \\
\hline Global Severity Index (GSI) & $7(10.8)$ & $61(18.9)$ & $8(6.7)$ & $11.30^{* *}$ & .15 \\
\hline
\end{tabular}

$* p<.05 ; * * p<.01$ 
Table 4

Univariate logistic regression for variables associated with GSI T-score $\geq 63$

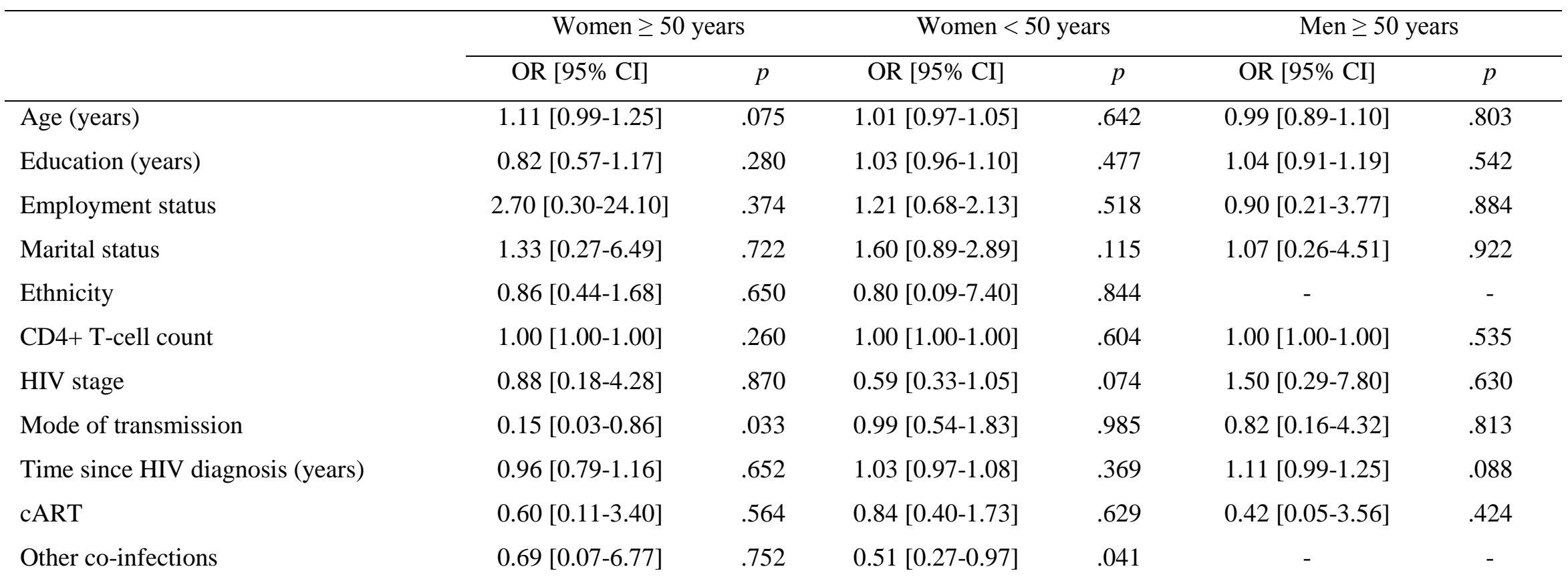

Note: Employment status [0= Employed; 1 = Unemployed or not currently working]; Marital status [0 = Living alone; $1=$ Living with partner]; HIV stage $[0=$ Asymptomatic; $1=$ Symptomatic/AIDS $]$; Mode of transmission $[0=$ Other; $1=$ Sexual $]$ : cART $[0=$ No; $1=$ Yes $]$; Other co-infections $[0=$ No; $1=$ Yes $]$. 
Table 5

Univariate and multivariate logistic regression analysis of study variables associated with GSI T-score $\geq 63(N=508)$

\begin{tabular}{|c|c|c|c|c|}
\hline & \multicolumn{2}{|c|}{ Univariate analysis } & \multicolumn{2}{|c|}{ Multivariate analysis $^{\mathrm{a}}$} \\
\hline & OR $[95 \% \mathrm{CI}]$ & $P$ & OR $[95 \% \mathrm{CI}]$ & $p$ \\
\hline Study groups & & .005 & & .027 \\
\hline Women $<50$ years vs. Men $\geq 50$ years & $3.26[1.51-7.04]$ & .003 & $2.67[1.22-5.84]$ & .014 \\
\hline Women $\geq 50$ years vs. Men $\geq 50$ years & $1.69[0.58-4.89]$ & .333 & $1.41[0.46-4.29]$ & .548 \\
\hline Education (years) & $1.03[0.97-1.09]$ & .315 & - & - \\
\hline Employment status & $1.23[0.74-2.02]$ & .426 & - & - \\
\hline Marital status & $1.59[0.96-2.65]$ & .071 & $1.56[0.91-2.68]$ & .104 \\
\hline Ethnicity & $0.86[0.46-1.60]$ & .631 & - & - \\
\hline CD4+ T-cell count & $1.00[1.00-1.00]$ & .590 & - & - \\
\hline HIV stage & $0.68[0.41-1.13]$ & .134 & $0.75[0.44-1.28]$ & .291 \\
\hline Mode of transmission & $0.76[0.44-1.30]$ & .312 & - & - \\
\hline Time since HIV diagnosis (years) & $1.04[0.99-1.09]$ & .089 & $1.03[0.98-1.08]$ & .225 \\
\hline cART & $0.77[0.41-1.45]$ & .426 & - & - \\
\hline Other co-infections & $0.56[0.31-1.01]$ & .055 & $0.66[0.35-1.24]$ & .198 \\
\hline
\end{tabular}

Note: Employment status [0= Employed; 1 = Unemployed or not currently working]; Marital status [0 = Living alone; 1 = Living with partner]; Ethnicity $[0=$ Caucasian; $1=$ African/Other/Unknown); HIV stage $[0=$ Asymptomatic; $1=$ Symptomatic/AIDS $]$; Mode of transmission $[0=$ Other; $1=$ Sexual]: cART $[0=$ No; $1=$ Yes]; Other co-infections $[0=$ No; $1=$ Yes $]$.

${ }^{a}$ Only the covariates associated with GSI T-score $\geq 63$ in the univariate analysis (two-sided $p$-value $<.20$ ) were included in the multivariate logistic regression model. 